\title{
On the Observational (Non)Equivalence of Money Growth and Interest Rate Rules
}

\author{
Stéphane Auray* $\quad$ Patrick Fève $^{\dagger}$
}

Revised Version: April 2007

\begin{abstract}
In this paper we discuss the observational equivalence between two monetary policy rules: a constant money growth rule and an interest rate rule. From the equilibrium conditions of a sticky prices model, we consider: (i) the Taylor rule parameter implied by the model with exogenous money supply; and (ii) the parameter of the money growth process implied by the model with an interest rate rule. We then compare the parameters of the two monetary rules in each case to evaluate the equivalence property. We show that the two monetary policy rules are not observationally equivalent (except in a very implausible empirical case) and therefore that the way of modeling monetary policy is of importance.
\end{abstract}

Keywords: monetary policy, sticky prices, sunspots.

JEL Class.: E4, E5.

\footnotetext{
*Université Charles de Gaulle, Lille 3, GREMARS and CIRPÉE (Canada). Correspondence address: Université Charles de Gaulle, Lille 3, Maison de la Recherche, Domaine du Pont de bois, BP 60149, 59653 Villeneuve d'Ascq cedex, France. Email: stephane.auray@univ-lille3.fr.

${ }^{\dagger}$ Université de Toulouse, GREMAQ, IDEI and Banque de France. Correspondence address: GREMAQUniversité de Toulouse I, manufacture des Tabacs, bât. F, 21 allée de Brienne, 31000 Toulouse, France. Email: patrick.feve@univ-tlse1.fr. We would like to thank Paul Beaudry, Fabrice Collard, Arianna Degan, Gordon, Fisher, Javier Diaz-Giménez, Aubhik Khan, Tim Kehoe, Tatyana Koreshkova, Louis Phaneuf, Franck Portier and Victor Rios-Rull for helpful comments. This paper has benefited from discussions during presentations at ENTER-Jamboree (Toulouse, 2002), T2M conference (Paris, 2002), Dynamic Macroeconomics Workshop (Vigo, 2002), EEA (Venice, 2002), Université du Québec à Montréal (Montréal, 2004), Queen's University (Kingston, 2005) and Universidad Carlos III (Madrid, 2005). We would like to thank the editor, Theodore Palivos, and a referee for insightful comments. We remain solely responsible for any error or omission. The views expressed therein are those of the authors and do not necessarily reflect those of the Banque de France.
} 


\section{INTRODUCTION}

In this paper, we study under which conditions observational equivalence between interest rate rule and money growth rule may exist in a sticky prices economy. The question matters for any economist who wants to model monetary policy. Observational equivalence between the two monetary policies would lead the model builders not to care about it. Conversely, if observational equivalence does not hold, the way monetary policy is represented matters. We show that observational equivalence between the two monetary policy rules is a very special case and certainly not a general result.

A huge part of the literature is concerned by the monetary transmission mechanism (real and/or nominal frictions) and does not focus on the consequences of the way monetary policy is modeled. DSGE models either include a Taylor rule (see Taylor, 1993 and 1999) to represent monetary policy (see Rotemberg and Woodford, 1999 and Boivin and Giannoni, 2005), or consider an exogenous money growth rule (see Christiano, Eichenbaum, and Evans, 1997 and 2005 and Altig, Christiano, Eichenbaum, and Linde, 2005). Further, Structural Vector Autoregression assumes that monetary policy changes can be represented by shocks to Federal Fund Rate and/or Non-Borrowed Reserve (see Christiano, Eichenbaum, and Evans, 1998). They do so by arguing that the way monetary policy is modeled does not matter.

Does it matter? It is known that the way in which policy is described matters because the interest rate process that is generated by an exogenous money growth rule may or may not satisfy the Taylor Principle for equilibrium determinacy. The converse is also true. However, if one does not abstract from this technical issue but consider indeterminate cases when they appear, the previous question still holds. To go farther answering this issue, we discuss the observational equivalence between two representations of monetary policy. In a first case, monetary policy is represented as a stationary stochastic process of the growth rate of money supply. In the second, monetary policy is of a Taylor-type rule, i.e. a relationship between interest rate and expected inflation. ${ }^{1}$

We start from a general equilibrium monetary model, a sticky prices model, that is sufficiently simple to get analytical and explicit results. ${ }^{2}$ We use this model as a Data Generating

\footnotetext{
${ }^{1}$ This paper is related to Vegh (2001) who identifies basic equivalences between monetary rules in a continuous time environment. It further relates to Schabert (2005) who analyzes the relation between interest rate targets and money supply in a cash-in-advance model. Notice that we also do so by assuming that the Taylor-type rule incorporates the current inflation rate.

${ }^{2}$ This model is chosen because this approach is based on the idea that temporary nominal price rigidities
} 
Process (DGP) that allows to reproduce some features of actual data, which are taken as the realization of an unknown stochastic process. Following a common econometric practice (see Clarida, Galí and Gertler, 1999), we first use GMM to estimate the relation between the nominal interest rate and the expected inflation under the model with exogenous money growth rule. Second, using OLS, we estimate the money growth relationship under the model with an interest rate rule.

We first discuss the results when the true monetary policy is the exogenous money growth. When the parameters that describe private behavior in this economy are calibrated with respect to their empirical counterparts, the implied estimate of the Taylor rule parameter is strictly greater than one, provided the growth rate of money supply displays positive serial correlation. It follows that the estimated value of this parameter is close to the ones of estimated Taylor rule (see Clarida, Galí and Gertler, 2000). ${ }^{3}$ The estimated parameter of the Taylor-type rule turns out to be a non-linear decreasing function of the money growth parameter that accounts for the persistence of money injections. When money injection are very persistent, the nominal interest rate weakly reacts to expected inflation and the real interest rate remains almost constant. Conversely, when money injection is almost white noise, the estimated central bank reaction function implies that the nominal interest rate strongly responds to expected inflation. It follows that "active" Taylor rule are associated with weak persistence of money injection.

We then consider the stochastic process of money growth implied by the sticky prices model with a Taylor rule. As shown by Carlstrom and Fuerst (2001), including Taylor rule in this model leads to indeterminacy.

We restrict our analysis to the indeterminate case for two reasons. We show that when monetary policy is represented by an exogenous money growth rule, the Taylor rule parameter depends on two parameters that describe private behavior and on the money growth rule parameter. For any empirical plausible value of these parameters, the Taylor rule parameter will be greater than one. This leads to conclude that observational equivalence may appear only if the Taylor rule parameter is greater than one. In this case, the model generates indeterminacy (see Carlstrom and Fuerst, 2001). We therefore have to focus on the indeterminacy provide the key friction that gives rise to nonneutral effects of monetary policy (see Clarida, Galí and Gertler, 1999 for a discussion). In addition, the observational equivalence results are consistent in both sticky and flexible prices frameworks.

${ }^{3}$ Assuming that the central bank follows an endogenous money growth rule leads to the same conclusions. 
case to study the observational equivalence properties between the different monetary policy rules. Second, and more important, when studying observational equivalence the interpretation of the parameters of the two monetary policy rules matters. In the determinate case with the Taylor rule, one may be willing to study observational equivalence by assuming that monetary policies (money growth rule and interest rate rule) are represented by an $\operatorname{AR}(1)$ process. However, the parameters do not deserve the same interpretation in that case: the Taylor rule parameter corresponds to the smoothness parameter of the money shock while the money growth rule parameter is the persistence parameter of the shock. In the indeterminate case, the same interpretation may be given to both parameters. For this additional and important normative reason, we exclude the determinate case from our study.

We determine the dynamic properties of the sticky price model when monetary policy is represented by a Taylor-type rule. Four sunspots affect the growth rate of money. However, only one of them may lead to conclude that monetary policies are observationally equivalent. We then focus on this sunspot that is due to real indeterminacy. In such a case, we show that when the effect of labor supply behavior and technology do not account for the dynamics of the model, we retrieve the observational equivalence between the two monetary policies. The interpretation of the estimated Taylor rule or that of the estimated process of money growth leads to the same conclusion, i.e. an aggressive Taylor rule can be viewed as weakly persistent money growth, and vice versa. However, it is not relevant to discard labor supply and technology effects. Researchers can not think of any serious quantitative model that could match the labor market stylized facts of, say the US economy, by discarding the role of these effects. As a matter of fact, we show that when the effect of labor supply behavior and technology do not account for the dynamics of the model, there is no observational equivalence between interest rate and money growth rule. Therefore, the modeling choice of monetary policy is of great importance.

The paper is organized as follows. A first section presents the monetary model and the equilibrium associated with the two representations of monetary policy. The second section presents the estimation results of the Taylor rule parameter under the sticky prices model with exogenous money growth rule. In section three, we estimate the parameter of the money growth process under the model with a Taylor rule and discuss observational equivalence. A last section concludes. 


\section{THE MONETARY ECONOMY}

This section is devoted to an exposition of the model. We set up a sticky prices model with monopolistic competition, consistent with the monetary transmission mechanism (see e.g., Hairault and Portier, 1993, King and Wolman, 1996, Galí, 1999, and Ireland, 2001). The model is deliberately stylized to highlight structural relations between nominal variables (inflation, interest rate and money growth) and to determine analytically the solution of the model.

\subsection{Households}

The economy comprises a unit mass continuum of identical, infinitely-lived households. Each household has preferences over consumption and leisure represented by the following intertemporal utility function :

$$
E_{t} \sum_{\tau=t}^{\infty} \beta^{\tau-t}\left[\log \left(C_{\tau}\right)-\frac{h_{\tau}^{1+\chi}}{1+\chi}\right],
$$

where $\beta \in(0,1)$ is the discount factor, $\chi \geq 0$ and $h_{t}$ denotes the number of hours supplied by the household. $E_{t}$ denotes the expectation operator conditional on the information set available in period $t$.

A representative household enters period $t$ with nominal bonds $B_{t}$ and nominal balances $M_{t}$ brought from the previous period. During the period, the household supplies labor $h_{t}$ at the real wage $W_{t} / P_{t}$. In addition, it receives a lump-sum transfer from the monetary authorities in the form of cash equal to $T_{t}$, profit from the firm $\Pi_{t}$, and real interest rate payments from bond holdings $\left(\left(R_{t-1}-1\right) B_{t} / P_{t}\right)$. These revenues are used to buy consumption goods $\left(C_{t}\right)$, money balances $\left(M_{t+1}\right)$ and nominal bonds $\left(B_{t+1}\right)$ in the next period. Therefore, the budget constraint can be written as

$$
B_{t+1}+M_{t+1}+P_{t} C_{t}=W_{t} h_{t}+R_{t-1} B_{t}+M_{t}+T_{t}+\Pi_{t}
$$

The household faces a cash-in-advance (CIA) constraint of the form:

$$
P_{t} C_{t} \leqslant M_{t}+T_{t}+R_{t-1} B_{t}-B_{t+1} .
$$

Money is held for transaction motives. The household carries cash to purchase consumption goods. We restrict our attention to equilibria with strictly positive nominal interest rate so that the cash constraint is always binding. We let $C_{t}$ denotes a composite consumption index 
defined by :

$$
C_{t}=\left(\int_{0}^{1} C_{i, t}^{(\varepsilon-1) / \varepsilon} d i\right)^{\varepsilon /(\varepsilon-1)},
$$

where $C_{i, t}$ is the quantity of good $i \in[0,1]$ consumed in period $t$ and $\varepsilon>1$ is the elasticity of substitution among consumption goods. The price of good $i$ is given by $P_{i, t}$ and the general price index $P_{t}$ is given by:

$$
P_{t}=\left(\int_{0}^{1} P_{i, t}^{1-\varepsilon} d i\right)^{1 /(1-\varepsilon)} .
$$

The household determines its optimal consumption/saving, labor supply and money and bond holding plans, maximizing utility subject to the budget and cash-in-advance constraint. The quantity of good $i$ consumed in period $t$ is given by:

$$
C_{i, t}=\left(\frac{P_{i, t}}{P_{t}}\right)^{-\varepsilon} C_{t}
$$

Consumption behavior together with labor supply yields

$$
h_{t}^{\chi} \frac{P_{t}}{W_{t}}=\beta E_{t} \frac{P_{t}}{P_{t+1}} \frac{1}{C_{t+1}}
$$

whereas nominal return of bond holdings is given by:

$$
R_{t}=h_{t}^{-\chi} \frac{W_{t}}{P_{t} C_{t}}
$$

This last equation, together with the CIA constraint, determines money demand where, for a given real wage, real balances are a decreasing function of the nominal interest rate.

\subsection{Firms}

In this economy, there is a continuum of firms distributed uniformly on the unit interval. Each firm is indexed by $i \in[0,1]$ and produces a differentiated good with a technology which implies diminishing returns to hours worked

$$
Y_{i, t}=A h_{i, t}^{\alpha}
$$

with $\alpha \in(0,1]$ and where $A$ is a strictly positive scale parameter. At the end of period $t-1$, i.e. before observing the realization of the money supply shock in period $t$, firm $i$ sets the price $P_{i, t}$ at which it will be selling good $i$ during period $t$, for a given aggregate price $P_{t}$. The firm is owned by the household, and pays its profits out to the household at the end of 
each period. Because of the CIA constraint on household consumption, the firm discounts its profit using $\Phi_{t+1}=\beta /\left(P_{t+1} C_{t+1}\right)$. Therefore, for a given wage $W_{t}$, the firm $i$ will seek to

$$
\max _{P_{i, t}} E_{t-1}\left[\Phi_{t+1}\left(P_{i, t} Y_{i, t}-W_{t} h_{i, t}\right)\right]
$$

subject to

$$
Y_{i, t}=\left(\frac{P_{i, t}}{P_{t}}\right)^{-\varepsilon} C_{t}
$$

The firm's optimal pre-set price is thus given by:

$$
P_{i, t}=\frac{\varepsilon}{\alpha(\varepsilon-1)} \frac{E_{t-1}\left[\Phi_{t+1} W_{t}\left(Y_{i, t} / A\right)^{1 / \alpha}\right]}{E_{t-1}\left[\Phi_{t+1} W_{t} Y_{i, t}\right]} .
$$

\subsection{The Government}

The government issues nominal bonds $B_{t}$ to finance open market operations. The government budget constraint is

$$
M_{t+1}+B_{t+1}=M_{t}+T_{t}+R_{t-1} B_{t}
$$

with $M_{0}$ and $B_{0}$ given.

\subsection{The Monetary Policy}

We consider two alternative monetary policies. In the first case, as is standard in monetary economics, monetary policy is described by an exogenous money growth rule. In the second case, monetary policy is represented by a Taylor-type rule describing how a central bank sets the nominal interest rate in response to economic variables. In what follows, we provide the details of the monetary rules we consider. ${ }^{4}$

\subsubsection{Exogenous Money Growth Rule}

Money is exogenously supplied according to the following rule

$$
M_{t+1}=\gamma_{t} M_{t},
$$

in which the gross rate of money growth $\gamma_{t}$ follows an $\mathrm{AR}(1)$ process:

$$
\log \left(\gamma_{t}\right)=\rho_{\gamma} \log \left(\gamma_{t-1}\right)+\left(1-\rho_{\gamma}\right) \log (\bar{\gamma})+\varepsilon_{t}^{\gamma} .
$$

\footnotetext{
${ }^{4}$ As suggested by a referee, we also consider an endogenous money growth rule (see Section 2) and a more familiar form of the Taylor rule which incorporates the current inflation rate (see Section 3).
} 
$\varepsilon_{t}^{\gamma}$ is white noise with unit variance $\sigma_{\varepsilon^{\gamma}}>0$ and $\left|\rho_{\gamma}\right|<1$. In this case, the Central Bank could implement what is essentially the classic textbook policy of dropping freshly printed money from a helicopter. A money-financed cut is then essentially equivalent to Milton Friedman's famous "helicopter drop of money".

\subsubsection{Interest Rate Rule}

We specify the following Taylor-type rule

$$
\widehat{R}_{t}=\eta E_{t} \widehat{\pi}_{t+1}
$$

where a hat denotes the percentage of deviation from the long run value. This Taylor-type rule incorporates only the expected inflation rate and aims at describing the joint behavior of the nominal interest rate and expected inflation. We choose this Taylor-type rule for many reasons. First, we adopt this specification as our benchmark Taylor-type rule because it simplifies the exposition of results. Resorting to such a parsimonious rule allows us to synthesize the complex process of monetary policy with the minimum number of parameters. Nevertheless, we check the robustness of our results to different forms of this rule and since the results are similar, we stick to this simple form of the Taylor rule. Second, there are many empirical findings that were obtained using this rule. For example, Batini and Haddane (1998), and Clarida, Galí and Gertler (1998) and (2000) provide GMM estimates of this rule and strong evidence of an increase in the real interest rate facing higher expected inflation. Most of empirical studies suggests an estimated value of $\eta$ significantly greater than one and in some cases close to two (see Kozicki (1999) for a survey). Third, previous empirical results suggest that the estimated parameter of the (expected) output gap is marginally significant for the Volcker-Greenspan era (see Clarida, Galí and Gertler, 2000). Conversely, estimates of $\eta$ are significant, positive and exceed unity in most cases (see Taylor, 1999 and Clarida, Galí and Gertler, 2000). Fourth, such rules have been shown to follow actual monetary policy rather well in a number of countries (see Clarida, Galí and Gertler, 2000). Last but not least, similar reaction functions are used in the Quarterly Projection Model of the Bank of Canada and in the Forecasting and Policy System of the Reserve Bank of New Zealand. 


\subsection{Equilibrium Conditions}

An equilibrium is a sequence of prices and allocations, such that each price, allocations maximize both profits and utility, and all markets clear. In a symmetric equilibrium, all firms will set the same price $P_{t}$ and choose identical outputs and hours. Goods market clearing requires $C_{t}=C_{i, t}=Y_{t}=Y_{i, t}$ for all $i \in[0,1]$ and all $t$. The equilibrium conditions can be approximated by log-linearization about the deterministic steady state:

$$
\begin{aligned}
\widehat{R}_{t} & =E_{t} \widehat{\gamma}_{t+1}, \\
\widehat{\pi}_{t} & =\widehat{\gamma}_{t}+\widehat{y}_{t-1}-\widehat{y}_{t}, \\
\widehat{y}_{t} & =\widehat{\gamma}_{t}-E_{t-1} \widehat{\gamma}_{t}-\frac{\alpha}{1+\chi} E_{t-1} \widehat{\gamma}_{t+1},
\end{aligned}
$$

where $\gamma_{t}=M_{t+1} / M_{t}$ denote the gross rate of money growth.

\subsubsection{Equilibrium conditions with a Money Growth Rule}

Using the money growth rule (1) and the previous equilibrium conditions, we obtain the following model solution:

$$
\begin{aligned}
\widehat{R}_{t} & =\rho_{\gamma} \widehat{\gamma}_{t} \\
\widehat{\pi}_{t} & =\left(1+\rho_{\gamma}\left(1+\frac{\alpha \rho_{\gamma}}{1+\chi}\right)\right) \widehat{\gamma}_{t-1}-\rho_{\gamma}\left(1+\frac{\alpha \rho_{\gamma}}{1+\chi}\right) \widehat{\gamma}_{t-2}, \\
\widehat{y}_{t} & =\widehat{\gamma}_{t}-\rho_{\gamma}\left(1+\frac{\alpha \rho_{\gamma}}{1+\chi}\right) \widehat{\gamma}_{t-1} .
\end{aligned}
$$

\subsubsection{Equilibrium conditions with a Taylor Rule}

As shown by Carlstrom and Fuerst (2001), the inclusion of a Taylor rule in this model leads to indeterminacy. Under the interest rate policy (2), money supply is endogenous. From (4) and (2), it follows that

$$
E_{t} \widehat{\gamma}_{t+1}=\frac{\eta}{1-\eta}\left(\widehat{y}_{t}-E_{t} \widehat{y}_{t+1}\right)
$$

Now, using (5) and taking expectations at period $t-1$, we obtain the first-order linear difference equation for output

$$
E_{t-1} \widehat{y}_{t+1}=\frac{\alpha \eta-(1+\chi)(\eta-1)}{(1+\chi) \eta} E_{t-1} \widehat{y}_{t}
$$

The dynamic properties of the equilibrium critically depend on the value of $\eta$ with respect to the unit circle. We define $\eta^{\star}$, with $\eta^{\star} \equiv(1+\chi) /(2(1+\chi)-\alpha)$, as a threshold value 
for indeterminacy. When $\eta<\eta^{\star}$, the equilibrium is locally determinate. Conversely, the equilibrium is locally indeterminate when $\eta>\eta^{\star}$. The threshold value $\eta^{\star}$ is positive and can exceed one provided that $\chi$ (resp. $\alpha$ ) is sufficiently small (resp. large). We concentrate on positive values of $\eta$, because previous empirical studies suggest that this parameter is strictly greater than one (see Taylor, 1999 and Clarida, Galí and Gertler 1998, 2000, among others). In this case, aggressive policies $(\eta>1)$ lead to real indeterminacy. As stated by Carlstrom et Fuerst (2001), this aggressive monetary policy is the basis of indeterminacy since it implies that nominal and real interest rates move along the same line. ${ }^{5}$

Let

$$
\varphi=\frac{\alpha \eta-(1+\chi)(\eta-1)}{(1+\chi) \eta}
$$

whereupon equation (9) becomes:

$$
\widehat{y}_{t}=\varphi \widehat{y}_{t-1}+\varepsilon_{t}^{y, 1}+\varepsilon_{t-1}^{y, 2}-\varphi \varepsilon_{t-1}^{y, 3}
$$

where $\varepsilon_{t}^{y, 1}, \varepsilon_{t-1}^{y, 2}$ and $\varepsilon_{t-1}^{y, 3}$ are martingale difference sequences satisfying $E_{t-2} \varepsilon_{t}^{y, 1}=0, E_{t-2} \varepsilon_{t-1}^{y, 2}=$ 0 and $E_{t-2} \varepsilon_{t-1}^{y, 3}=0$. These terms are sunspot variables which are consistent with rational expectations equilibrium. Therefore, when indeterminate, the sticky prices model with a Taylor rule implies three types of sunspot variables that affect real variables. The fact that $\varepsilon_{t}^{y, 2}$ and $\varepsilon_{t}^{y, 3}$ have similar quantitative implications (as may be easily verified) allows us to focus on a single sunspot (see discussion bellow).

Moreover, nominal indeterminacy occurs for any value of $\eta$ and $\varphi$ :

$$
\widehat{\gamma}_{t}=\varepsilon_{t}^{g}+\frac{\eta(1-\varphi)}{1-\eta} \widehat{y}_{t-1}-\frac{\eta}{1-\eta} \varepsilon_{t-1}^{y, 2}+\frac{\eta \varphi}{1-\eta} \varepsilon_{t-1}^{y, 3}
$$

where $E_{t-1} \varepsilon_{t}^{g}=0$. By nominal indeterminacy, we mean that the inflation rate is free, i.e. there is nothing to pin down the initial growth rate of money. Consequently, the growth rate of money is determined by four sunspots.

Therefore, aggregate fluctuations in deviation from the deterministic steady-state, depend on the parameters of the monetary policy $\eta$, the parameters that describe the private behavior $(\chi$ and $\alpha$ ) and on those summarizing the sunspot variables, i.e. their relative variances.

\footnotetext{
${ }^{5}$ As explained by Carlstrom et Fuerst (2001), the mechanism that leads to indeterminacy is as follows. Consider a sunspot-driven increase in current consumption. When $\eta>\eta^{\star}$, the intertemporal allocation of saving lowers the real interest rate and thus the nominal interest rate. The intratemporal allocation raises real balances and thus consumption increases due to the CIA constraint. This increases in consumption completes the circle because it insures that initial beliefs are rational.
} 
Given the solution of the two models, we consider below: (i) the Taylor rule parameter $\left(\eta_{\rho}\right)$ implied by the sticky prices model with exogenous money supply, and (ii) the parameter of the money growth process $\left(\rho_{\eta}\right)$ implied by the model with a Taylor rule. We then compare the two parameters in order to evaluate some equivalence properties.

\section{The Estimated Interest Rate Rule}

Any monetary rule must be estimated using aggregate data which are the realizations of economic equilibrium, i.e. a reduced form that defines a set of endogenous variables in terms of exogenous and predetermined variables. Therefore, the econometrician must use a set of relevant instrumental variables in order to identify and estimate the structural equation that characterizes central bank behavior. Empirical studies on the Taylor rule generally use lagged inflation and the lagged nominal interest rate as instrumental variables (see Clarida, Galí and Gertler, 1998, 2000). Using the same procedure, we estimate the relation between the nominal interest rate and expected inflation under the sticky prices model with an exogenous money growth rule.

We assume that the monetary model (6)-(8) with exogenous money growth rule constitutes the "true" Data Generating Process (DGP). This DGP permits actual data to be generated. Such data are taken as the realization of a stochastic process, that is, unknown to the econometrician. The features in which we are interested include conditional moments of the nominal interest rate and inflation. Rule (2) can be expressed in terms of observable :

$$
\widehat{R}_{t}=\eta_{\rho} \widehat{\pi}_{t+1}+\varepsilon_{t+1}
$$

where $\varepsilon_{t+1}=-\eta_{\rho}\left(\widehat{\pi}_{t+1}-E_{t} \widehat{\pi}_{t+1}\right)$. The econometrician observes values of the nominal interest rate $\widehat{R}_{t}$ and the inflation rate $\widehat{\pi}_{t+1}$ and uses these data as actual data without any explicit knowledge about the DGP. To estimate central bank behavior, the econometrician uses a set of instrumental variables that aim at describing informative shifts in money demand behavior. For simplicity and tractability, we assume that the econometrician uses a single instrument. As we are interested in co-movements of the nominal interest rate and inflation, the necessary condition for identification of the central bank policy function is fulfilled. Let $z_{t}$ denote a single instrument known in period $t$. To be a valid instrument $z_{t}$ must satisfy the following orthogonality condition

$$
E\left(\varepsilon_{t+1} z_{t}\right)=0,
$$


or equivalently

$$
E\left(\left(\widehat{R}_{t}-\eta_{\rho} \widehat{\pi}_{t+1}\right) z_{t}\right)=0 .
$$

Equation (13) is the basis for GMM estimation of the parameter $\eta$. Since the number of orthogonality conditions is equal to the number of parameters of interest, it follows that the GMM estimator (or IV estimator in this simple case) is free from any weighting matrix and can be obtained directly as the sample counterpart of (13). ${ }^{6}$ Following previous empirical work (see Clarida, Galí and Gertler, 2000), an appropriate instrumental variable is the once lagged inflation rate. ${ }^{7}$ The orthogonality condition (13) becomes:

$$
E\left(\left(\widehat{R}_{t}-\eta_{\rho} \widehat{\pi}_{t+1}\right) \widehat{\pi}_{t-1}\right)=0 .
$$

From (14), the plim of the GMM estimator $\eta_{\rho}$ is thus given by:

$$
\eta_{\rho}=\frac{\operatorname{Cov}_{\rho}\left(\widehat{R}_{t}, \widehat{\pi}_{t-1}\right)}{\operatorname{Cov}_{\rho}\left(\widehat{\pi}_{t+1}, \widehat{\pi}_{t-1}\right)} .
$$

The GMM estimator $\eta_{\rho}$ is obtained from the autocovariance functions of the processes of inflation and nominal interest rate.

Proposition 1. The plim of the GMM estimator $\eta_{\rho}$ under the sticky price model with exogenous money growth rule is given by:

$$
\eta_{\rho}=\frac{1+\chi}{(1+\chi)-\alpha\left(1-\rho_{\gamma}\right)}
$$

The econometrician could also use the current inflation rate as an instrumental variable, because, in the sticky price model, inflation responds with one lag to monetary innovations. Current inflation is thus uncorrelated with the error term $\varepsilon_{t}^{\gamma}$.

We study the evolution of the GMM estimator $\widehat{\eta}_{\rho}$ of $\eta$ with respect to the three parameters $\chi, \alpha$ and $\rho_{\gamma}$. When $\alpha=1$ and $\chi=0$, the GMM estimator $\widehat{\eta}_{\rho}$ of $\eta$ is equal to $1 / \rho_{\gamma}$. It follows that the GMM estimator is strictly positive, provided the growth rate of money supply displays positive serial correlation. Further, when we consider values for $\rho_{\gamma}$ that correspond to the range of existing OLS estimates with $M 1$ and $M 2$ (in the interval $(1 / 2,2 / 3)$ ),

\footnotetext{
${ }^{6}$ The estimator is called a GMM estimator by an abuse of terminology. In fact, it is a IV estimator that corresponds to a GMM estimator at the limit.

${ }^{7}$ Clarida, Galí and Gertler (2000) include lagged inflation rates up to four lags. To keep tractable results, we do not introduce over-identifying conditions and consider only one lag inflation rate as the instrumental variable. However, our results are left unaffected when over-identifying conditions are considered.
} 
the estimated value of $\eta$ is close to those of previously estimated Taylor rules (see Clarida, Galí and Gertler (2000), tables II and III, p 157 and 160). ${ }^{8}$

In addition, it is easy to see that $\widehat{\eta}_{\rho}$ is decreasing in $\chi$. When labor supply is inelastic, the GMM estimator $\widehat{\eta}_{\rho}$ of $\eta$ leads to one. In such a case, the model exactly reproduces a Fisher equation. Indeed, when labor supply is inelastic, households cannot avoid the inflation tax created by monetary policy. Finally, $\widehat{\eta}_{\rho}$ is increasing in $\alpha$ and decreasing in $\rho_{\gamma}$. To study the evolution of the GMM estimator $\widehat{\eta}_{\rho}$ of $\eta$ with respect to $\rho_{\gamma}$, we calibrate $\chi$ and $\alpha$ with respect to their empirical counterparts. We set $\chi=1$ (see Christiano, Eichenbaum, and Evans, 2005 and Altig, Christiano, Eichenbaum, and Linde, 2005) and $\alpha=0.6$ (see Cooley and Prescott, 1995). We then let $\rho_{\gamma}$ free to vary within the interval $[0.2 ; 0.8]$ - which corresponds to a large enough interval to take into account all the plausible empirical values of this parameter - and plot the evolution of the GMM estimator $\widehat{\eta}_{\rho}$. Figure 1 clearly highlights that for

Figure 1: Implied value $\eta_{\rho}$

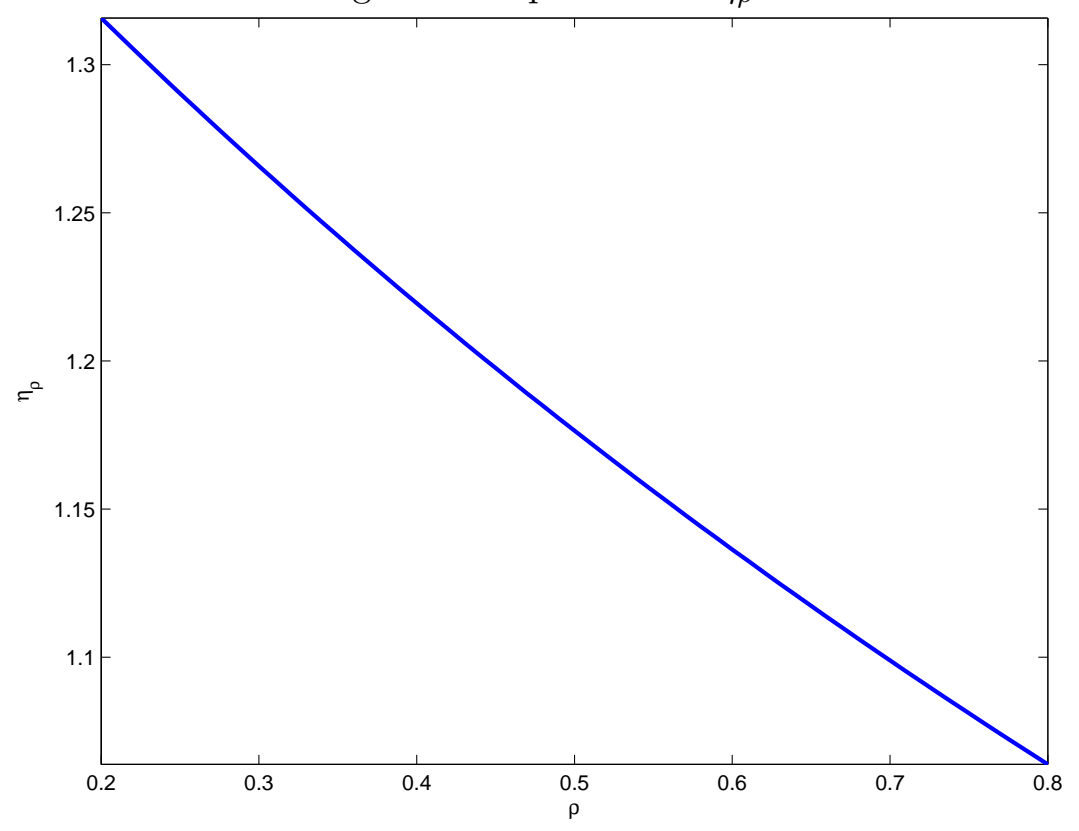

Note: The figure is obtained for $\chi=1$ and $\alpha=0.6$.

plausible values of the three parameters $\chi, \alpha$ and $\rho_{\gamma}$, the estimated value of $\eta$ is greater

\footnotetext{
${ }^{8}$ Notice that we checked the robustness of this result to the introduction of capital accumulation in the model. The results are unaffected also when we consider different types of shocks or when the lagged interest rate is introduced in the interest rate rule.
} 
than one and is not far from those of previously estimated Taylor rules (see Taylor, 1999 and Clarida, Galí and Gertler, 2000, among others). The GMM estimator $\widehat{\eta}_{\rho}$ of $\eta$ depends on $\rho_{\gamma}$ which summarizes monetary policy. The estimated parameter of the Taylor-type rule is a non-linear decreasing function of $\rho_{\gamma}$, which accounts for the persistence of money injections. When money injections are very persistent $\left(\rho_{\gamma} \rightarrow 1\right)$, the nominal interest rate weakly reacts to expected inflation and the real interest rate remains almost constant. Conversely, when money injections are almost white noise $\left(\rho_{\gamma} \rightarrow 0\right)$, the estimated central bank's reaction function implies that the nominal interest rate strongly responds to expected inflation. It follows that "active" Taylor rules - large positive values of $\eta$ - are associated with weak persistency of money injections.

We may also consider an endogenous money growth rule. In such a situation, the central bank adjusts the supply of money in response to changes in inflation. Let us assume the following simple rule:

$$
\widehat{\gamma}_{t}=\xi \widehat{\pi}_{t}+\widetilde{\gamma}_{t}
$$

where

$$
\widetilde{\gamma}_{t}=\rho_{\gamma} \widetilde{\gamma}_{t-1}+\varepsilon_{t}
$$

The properties of this rule, in terms of local price determination, have been examined by Black [1974] and more recently by Schabert [2006] by considering different fiscal policy regimes. We consider this rule for one main reason. In this case, the money growth rate depends on the inflation rate. In such a case, the central bank aims at stabilizing the inflation rate by adjusting the quantity of money in circulation in the economy. The Taylor rule considered in the paper is also a stabilizing rule. The two rules are therefore comparable in a deep sense. To ease the comparison, we plot on a same figure, the implied value $\eta_{\rho}$ when the money growth rule is assumed to be exogenous and endogenous. In the case where the money growth rule is endogenous, Figure 2 highlights that for plausible values of $\chi$ and $\alpha$ and for a large enough interval of values of $\xi$, the estimated value of $\eta$ is very close to one, and more importantly greater than one since $\xi$ is greater than -0.6. As a matter of fact, these estimated values are also close from those of previously estimated Taylor rules. For the same parameters, the estimated value of $\eta_{\rho}$ is greater than one when the money growth rule is exogenous. Therefore, our conclusion holds independent of whether the money growth rule is endogenous or exogenous. 
Figure 2: Implied value $\eta_{\rho}$

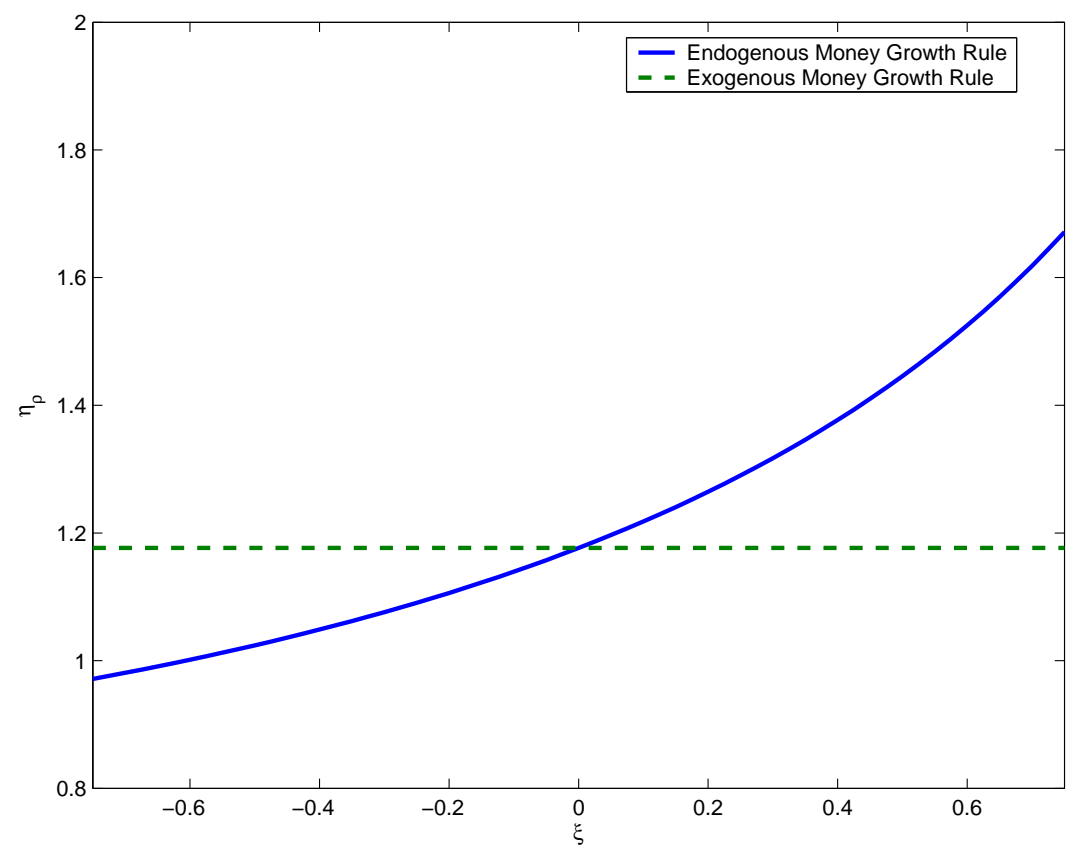

Note: The figure is obtained for $\chi=1, \alpha=0.6$ and $\rho_{\gamma}=0.5$.

Finally, we check the robustness of these results against different forms of the Taylor rule. As a matter of fact, the results are similar with other forms of the Taylor-type rule. For instance, we assume that the Taylor rule incorporates only the current inflation rate. We expose this case in the paper, because it is directly related to the previous robustness check. Indeed, one may also want to compare the observational equivalence result obtained under the model with endogenous money growth rule that incorporates the current inflation rate and a Taylor-type rule that also considers the current inflation rate. In this case, the implied static Taylor rule under the sticky price model with exogenous money supply rule has then the form:

$$
\widehat{R}_{t}=\eta_{\rho} \widehat{\pi}_{t}+\zeta_{t}
$$

where

$$
\eta_{\rho}=\frac{1+\chi}{(1+\chi)-\alpha\left(1-\rho_{\gamma}\right)} .
$$

The results are similar to those exposed in Proposition 1 with one additional term, $\zeta_{t}$, that 
is a stochastic variable which follows an $\operatorname{ARMA}(1,1)$ process:

$$
\zeta_{t}=\rho_{\gamma} \zeta_{t-1}+\rho_{\gamma}\left(\varepsilon_{t}-\frac{1}{\eta_{\rho} \rho_{\gamma}} \varepsilon_{t-1}\right) .
$$

It is therefore easy to see that the implied Taylor rule is more complicated than the previous one since it includes persistent shocks. These findings are in line with the results presented in Rudebusch [2002] and [2005]. These papers highlight that the persistence of the nominal interest rate is due to the persistence of monetary policy shocks. The results are thus at once more parsimonious when a Taylor rule that incorporates the expected inflation rate is considered. This leads us to choose in our exposition of the results a Taylor rule that does not consider the current inflation rate. For the same reason, we do not present the results when the Taylor rule incorporates the lagged interest rate.

\section{The Estimated Money Growth Rule}

We consider the stochastic process of money growth implied by the sticky price model with a Taylor rule. We will seek to verify whether or not there exists an observational equivalence between the two monetary rules.

From (10) and (11), the dynamics of the growth rate of money is given by:

$$
\widehat{\gamma}_{t}=\varphi \widehat{\gamma}_{t-1}+(1-\varphi L) \varepsilon_{t}^{g}+e_{t}^{1}+(1-L) e_{t}^{2}+(1-\varphi L) e_{t}^{3}
$$

where $L$ is the backshift operator. The random variables $e_{t}^{1}, e_{t}^{2}$ and $e_{t}^{3}$ are given by:

$$
\begin{aligned}
e_{t}^{1} & =\frac{\eta \varphi}{1-\eta} \varepsilon_{t-1}^{y 1}, \\
e_{t}^{2} & =-\frac{\eta}{1-\eta} \varepsilon_{t-1}^{y 2}, \\
e_{t}^{3} & =\frac{\eta \varphi}{1-\eta} \varepsilon_{t-1}^{y 3} .
\end{aligned}
$$

Some sunspot variables enter this equation. However, when money growth is governed by $\varepsilon_{t}^{g}$ or $e_{t}^{3}$, it is $i i d$, a result which is at odds with empirical evidence. In the same way, the random variable $e_{t}^{2}$ implies a unit root in the moving average, which is again not supported by the data. Consequently, we discard these three types of shocks from our analysis, because they imply that we can never find any observational equivalence between the two monetary policy rules. We concentrate our analysis on $e_{t}^{1}$ because it implies that the growth rate of money follows an $\mathrm{AR}(1)$ process, which can be potentially comparable with that of an exogenous money growth rule. 
Proposition 2. The plim of the OLS estimator under the sticky price model with a Taylor type rule is:

$$
\rho_{\eta}=\frac{\alpha \eta-(1+\chi)(\eta-1)}{(1+\chi) \eta}
$$

This proposition leads to important conclusions for quantitative researchers and policymakers. First, in the special case where $\alpha=1$ and $\chi=0$, the plim of the OLS estimator reduces to: $\rho_{\eta}=1 / \eta$, and thus we obtain the observational equivalence between the two rules. Second, this special case is not empirically relevant; and, except for this particular case, there does not exist any observational equivalence between the two monetary policy rules. Figure 3 highlights this result. To compute the figure we proceed as follows. First, we set values for $\rho_{\gamma}$ on a grid $[0.3,1]$. Second, we compute $\eta_{\rho}$ using the formula of Proposition 1. Third, we use the implied value of $\eta$ to compute $\rho_{\eta}$ using the formula of Proposition 3. If observational equivalence holds, the implied two curves in the $(\rho, \eta)$ plan must coincide. If not, there is no observational equivalence.

Figure 3: Rules and Implied Rules
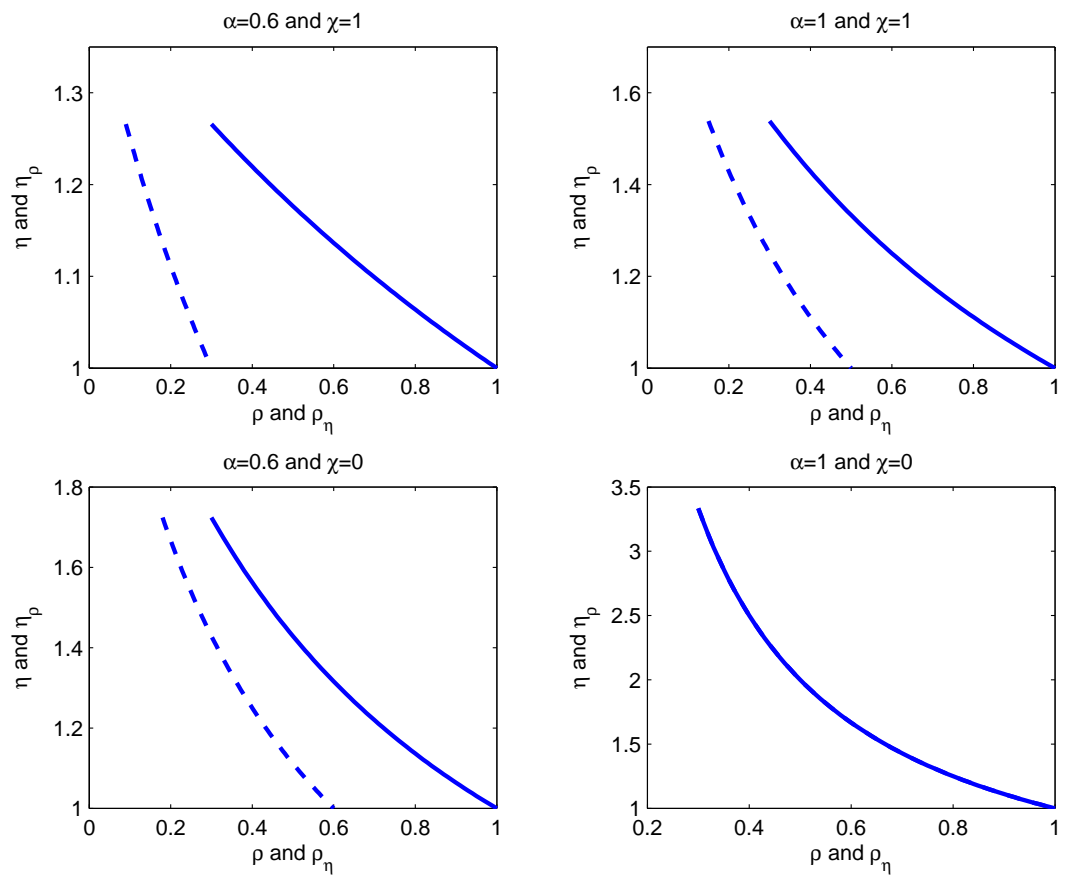

Note: The solid line represents the implies values of $\eta_{\rho}$ w.r.t $\rho_{\gamma}$; The dashed line represents the implied value of $\rho_{\eta}$ w.r.t. $\eta$. 
The figure clearly shows that observational equivalence between the two representations of the monetary policy is only a special case that depends on the parameters that describe private behavior in this economy. Therefore, the modeling choice for monetary policy is important because it yields very different dynamic properties.

What is driving this result may be explained as follows. In the model with exogenous money growth rule, inflation expectations are governed by the persistence of the inflation tax, i.e. the persistence parameter $\rho_{\gamma}$ of money supply. When $\rho_{\gamma}$ leads to 1 , expected inflation is equal to the nominal interest rate and thus $\eta_{\rho}$ leads to 1 . In the model with a Taylor rule, the dynamic behavior of endogenous money supply inherits the behavior of output. The autoregressive parameter in the output equation includes the Taylor rule parameter $\eta$, as well as the other parameters $\alpha$ and $\chi$ that describe private behavior. When the effect of these two parameters is canceled (i.e. when $\alpha=1$ and $\chi=0$ ), the autoregressive parameter will depend only on the Taylor rule parameter, and we retrieve the observational equivalence under this restricted version of the model. On the contrary, when the effect of labor supply behavior and technology account for the dynamics of the model, the observational equivalence vanishes.

\section{Concluding Remarks}

This paper discusses the observational equivalence between two representations of monetary policy. Firstly, monetary policy is represented by an exogenous money growth rule. Secondly, monetary policy is represented by an interest rate rule. This is done using a sticky prices economy. We consider (i) the Taylor rule parameter implied by the sticky prices model with exogenous money supply; and (ii) the parameter of the money growth process implied by the model with a Taylor rule. We compare the two parameters in order to evaluate some equivalence properties. We show that the two monetary policy rules are not observationally equivalent (except in a very implausible empirical case). Therefore, the modeling choice of monetary policy is important. 


\section{REFERENCES}

[1] Altig, D. Christiano, L.J., Eichenbaum, M. and J. Linde (2005) J., "Firms-Specific Capital, Nominal Rigidities and the Business Cycle", Mimeo.

[2] Batini, N. and A.G. Haldane (1998), "Forward-Looking Rules for Monetary Policy", NBER, working paper 6543.

[3] Black, F. (1974), "Uniqueness of the Price Level in Monetary Growth Models with Rational Expectations", Journal of Economic Theory, 7, pp. 53-65.

[4] Boivin, J. and M. Giannoni (2005), "Has Monetary Policy Become More Effective?", forthcoming Review of Economics and Statistics.

[5] Carlstrom, C. and T. Fuerst (2001), "Timing and Real Indeterminacy in Monetary Models", Journal of Monetary Economics, 47, pp. 285-298.

[6] Christiano, L.J., Eichenbaum, M. and C. Evans (1997), "Sticky Price and Limited Participation Models of Money: A Comparison", European Economic Review, 41, pp. 1201-1249.

[7] Christiano, L.J., Eichenbaum, M. and C. Evans (1998), "Modeling Money", NBER, working paper 6371.

[8] Christiano, L.J., Eichenbaum, M. and C. Evans (2005), "Nominal Rigidities and the Dynamics Effects of a Shock to Monetary Policy", Journal of Political Economy, 113, pp. $1-45$.

[9] Clarida, R., Galí , J. and M. Gertler (1998), "Monetary Policy Rules in Practice. Some International Evidence", European Economic Review, 42, pp. 1033-1067.

[10] Clarida, R., Galí, J. and M. Gertler (1999), "The Science of Monetary Policy: A New Keynesian Perspective", Journal of Economic Literature, XXXVII, pp. 1661-1734.

[11] Clarida, R., Galí, J. and M. Gertler (2000), "Monetary Policy Rules and Macroeconomic Stability: Evidence and Some Theory", Quarterly Journal of Economics, CXV, pp. 147180.

[12] Cooley, T. and E.C. Prescott (1995), "Economic growth and business cycles", in Frontiers of Business Cycle Research, Cooley, T. Ed., Princeton University Press, pp. 1-38. 
[13] Galí , J. (1999), "Technology, Employment and the Business Cycle: Do Technology Shocks Explain Aggregate Fluctuations?" American Economic Review, 89, pp. 249-271.

[14] Hairault, J.O. and F. Portier (1993), "Money, New-Keynesian Macroeconomics and the Business Cycle", European Economic Review, 37, pp. 1533-1568.

[15] Ireland, P. (2001), "Sticky-Price Models of the Business Cycle: Specification and Stability", Journal of Monetary Economics, 47, pp. 3-18.

[16] King, R. and A. Wolman (1996), "Inflation Targeting in a St Louis Model of the 21st Century", NBER, working paper 5507.

[17] Kozicki, S. (1999), "How Useful are Taylor Rules for Monetary Policy?", Federal Reserve Bank of Kansas City, Economic Review, second quarter.

[18] Rotemberg, J. and M. Woodford (1999), "Interest-Rate Rules in an Estimated StickyPrice Model", in Monetary Policy Rules, J. Taylor Ed., University of Chicago Press.

[19] Rudebusch, G.D. (2002), "Term structure evidence on interest rate smoothing and monetary policy inertia", Journal of Monetary Economics, 49, pp. 1161-1187.

[20] Rudebusch, G.D. (2006), "Monetary policy inertia: Fact or fiction?", International Journal of Central Banking, 2, pp. 85-136.

[21] Schabert, A. (2005), "Money Supply and the Implementation of Interest Rate Targets", ECB, working paper 483.

[22] Schabert, A. (2006), "Central Bank Instruments, Fiscal Policy Regimes, and The Requirements for Equilibrium Determinacy", Review of Economic Dynamics, 9, pp. 742-762.

[23] Taylor, J. (1993), "Discretion versus Policy Rule in Practice", in Canergie Rochester Conference on Public Policy, 39, pp. 195-214.

[24] Taylor, J. (1999), "An Historical Analysis of Monetary Policy Rules", in Monetary Policy Rules, J. Taylor Ed., University of Chicago Press.

[25] Vegh, C.A. (2001) , "Monetary Policy, Interest Rate Rules, and Inflation Targeting: Some Basic Equivalences", NBER, working paper 8684. 


\section{APPENDIX}

Proof of Proposition 1. An easy way to obtain Proposition 1 relies on the cross equation restrictions between these two variables. Indeed, expected inflation can be expressed as

$$
\begin{aligned}
E_{t} \widehat{\pi}_{t+1} & =\left(1+\rho_{\gamma}\left(1+\frac{\alpha \rho_{\gamma}}{1+\chi}\right)\right) \widehat{\gamma}_{t}-\rho_{\gamma}\left(1+\frac{\alpha \rho_{\gamma}}{1+\chi}\right) \widehat{\gamma}_{t-1}, \\
& =\left(1+\frac{\alpha \rho_{\gamma}}{1+\chi}\right)\left(\widehat{\gamma}_{t}-\rho_{\gamma} \widehat{\gamma}_{t-1}\right)+\left(\frac{\alpha \rho_{\gamma}+1+\chi-\alpha}{1+\chi}\right) \rho_{\gamma} \widehat{\gamma}_{t}, \\
& =\left(1+\frac{\alpha \rho_{\gamma}}{1+\chi}\right) \varepsilon_{t}^{\gamma}+\left(\frac{\alpha \rho_{\gamma}+1+\chi-\alpha}{1+\chi}\right) \widehat{R}_{t},
\end{aligned}
$$

and we obtain

$$
\widehat{R}_{t}=\frac{1+\chi}{1+\chi-\alpha\left(1-\rho_{\gamma}\right)} E_{t} \widehat{\pi}_{t+1}+\widetilde{\varepsilon}_{t}^{\gamma}
$$

where $\widetilde{\varepsilon}_{t}^{\gamma}=-\frac{1+\chi+\alpha \rho_{\gamma}}{1+\chi-\alpha\left(1-\rho_{\gamma}\right)} \varepsilon_{t}^{\gamma}$. In the sticky price model, expected inflation verifies $E_{t} \widehat{\pi}_{t+1}=$ $\widehat{\pi}_{t+1}$ and the previous expression is equivalent to:

$$
\widehat{R}_{t}=\frac{1+\chi}{1+\chi-\alpha\left(1-\rho_{\gamma}\right)} \widehat{\pi}_{t+1}+\widetilde{\varepsilon}_{t}^{\gamma}
$$

The error term $\widetilde{\varepsilon}_{t}^{\gamma}$ thus verifies

$$
E\left(\varepsilon_{t}^{\gamma} \mid \widehat{\pi}_{t-1}\right)=0
$$

since $\widehat{\pi}_{t-1}$ is a linear function of $\left\{\varepsilon_{t-1}^{\gamma}, \varepsilon_{t-2}^{\gamma}, \ldots\right\}$. Now, if we apply the conditional expectation operator to both sides of the equation, we obtain:

$$
E\left(\widehat{R}_{t} \mid \widehat{\pi}_{t-1}\right)=\frac{1+\chi}{1+\chi-\alpha\left(1-\rho_{\gamma}\right)} E\left(\widehat{\pi}_{t+1} \mid \widehat{\pi}_{t-1}\right)
$$

and we deduce that

$$
\eta_{\rho} \equiv \frac{1+\chi}{1+\chi-\alpha\left(1-\rho_{\gamma}\right)}=\frac{\operatorname{Cov}_{\rho}\left(\widehat{R}_{t}, \widehat{\pi}_{t-1}\right)}{\operatorname{Cov}_{\rho}\left(\widehat{\pi}_{t+1}, \widehat{\pi}_{t-1}\right)}
$$

Proof of Proposition 2. The plim of the OLS estimator satisfies

$$
\begin{aligned}
\rho_{\eta} & =\frac{\operatorname{Cov}_{\eta}\left(\widehat{\gamma}_{t}, \widehat{\gamma}_{t-1}\right)}{V_{\eta}\left(\widehat{\gamma}_{t}\right)}, \\
& =\varphi+\frac{\operatorname{Cov}_{\eta}\left(e_{t}^{1}, \widehat{\gamma}_{t-1}\right)}{V_{\eta}\left(\widehat{\gamma}_{t}\right)}, \\
& =\frac{\alpha \eta-(1+\chi)(\eta-1)}{(1+\chi) \eta},
\end{aligned}
$$

as $\widehat{\gamma}_{t-1}$ is a linear function of $\left\{e_{t-1}^{1}, e_{t-2}^{1}, \ldots\right\}$. 